\title{
Inventarisasi kasus saat kegiatan belajar mengajar pelajaran IPA di SMP Muhammadiyah 1 dan SMP Muhammadiyah 2 Kalibawang
}

\author{
Septi Asri Lestari a, ${ }^{*}$, Anik Wulandari ${ }^{\text {b, } 2 \text {, Mutiah Putri Kuvitarani }}{ }^{\text {c, } 3}$ \\ a SMP Muhammadiyah 2 Kalibawang, Kulon Progo 55672 \\ b SMP Muhammadiyah 1 Kalibawang, Kulon Progo 55672 \\ c Prodi Pendidikan Biologi, Fakultas Keguruan dan Ilmu Pendidikan, Universitas Ahmad Dahlan \\ Jl. Jendral Ahmad Yani (Ringroad Selatan) Tamanan, Banguntapan, Bantul \\ Daerah Istimewa Yogyakarta 55191 \\ 1 morosmart@yahoo.com*;2 anikwulndari8@gmail.com; ${ }^{3}$ mutiah1500008013@webmail.uad.ac.id \\ *korespondensi penulis
}

\begin{abstract}
Abstrak
Problematika kegiatan belajar mengajar merupakan hal yang sering terjadi sehingga menjadi momok bagi guru dalam mencapai tujuan pembelajaran. Kasus yang terjadi saat kegiatan belajar mengajar pelajaran IPA di kedua sekolah tersebut diantaranya peserta didik yang bertingkah tidak sesuai peraturan sekolah dan tidak sesuai dengan etika sopan santun yang seharusnya sehingga dalam praktik kegiatan belajar mengajar guru banyak mengalami kesulitan dan tujuan pembelajaran tidak tercapai. Tujuan penelitian ini untuk menginventarisasi kasus-kasus yang terjadi saat kegiatan belajar mengajar pelajaran IPA di SMP Muhammadiyah 1 dan 2 Kalibawang.

Artikel ini ditulis berdasarkan perbandingan beberapa kasus yang ditemui dua guru pengampu mata pelajaran IPA di dua sekolah yang berbeda.

Hasil dari penelitian ini Pada SMP Muhammadiyah 1 Kalibawang terdapat 7 kasus dan SMP Muhammadiyah 2 Kalibawang terdapat 6 kasus. Di ke 13 kasus terebut 4 kasus yang sama. Yaitu membolos ke kantin sewaktu pelajaran, ngobrol pada saat pembelajaran, tidur di kelas, tidak mengguanakan bahasa yang sopan kepada gurunya, dan tugas-tugas yang tidak dikerjakan saat pembelajaran.
\end{abstract}

Kata kunci: IPA, kasus pembelajaran, SMP

\begin{abstract}
Problematics of teaching and learning activities are often the case that they become a scourge for teachers to achieve their learning objectives. Cases that occur when learning to teach SCIENCE lessons in both schools include learners who behave inappropriate school and not in accordance with the ethics of manners that should be so in the practice of activities Learning to teach many teachers difficulties and learning objectives are not achieved. The purpose of this research is to input the cases that occur when learning activities teaching SCIENCE lessons.

This article is written based on comparisons of some of the cases found in two teachers who are teaching SCIENCE courses in two different schools.

The results of this study in SMP Muhammadiyah 1 Kalibawang There are 7 cases and SMP Muhammadiyah 2 Kalibawang There are 6 cases. In 13 cases the same case 4 . That is to break into the cafeteria during lessons, chat during learning, sleep in class, do not provide polite language to teachers, and tasks that are not done during learning.
\end{abstract}

Keywords: IPA, learning case, SMP. 


\section{PENDAHULUAN}

Era globalisasi semakin mengedepankan ilmu pengetahuan tak terkecuali perkembangan teknologi dan informasi yang tanpa disadari membawa akses yang luas bagi semua orang tak terkecuali peserta didik mengeah pertama. Peserta didik usia SMP di tahun 2019 berkisar lahir antara tahun 2004-2007. Menurut Penelitian Bencsik, Csikos, dan Juhez (2016) dalam Putra (2017) anak dengan kelahiran tahun 1995-2010 termasuk kedalam generasi Z. Bagi generasi $\mathrm{Z}$ informasi dan teknologi adalah hal yang sudah menjadi bagian dari kehidupan mereka, karena mereka lahir dimana akses terhadap informasi, khususnya internet sudah menjadi budaya global, sehingga hal tersebut berpengaruh terhadap nilai - nilai, pandangan dan tujuan hidup mereka.

Budaya global yang sudah melekat pada keseharian generasi sekarang menimbulkan dampak negatif yang besar pula. Dampak negatif sangat terasa saat ini diantaranya perilaku sosial yang menyimpang dari tuntunan nilai moral.Dampak ini tidak jarang terjadi disekitar kita terutama terjadi pada peserta didik dan di lingkungan sekolah. Lunturnya etika, moral dan tanggung jawab menjadi permasalahan yang timbul ditengah-tengah perkembangan peserta didik.

Dampak lunturnya etika, moral dan tanggung jawab menjadi problematika saat kegiatan belajar dan momok bagi guru dalam mencapai tujuan pembelajaran. Kasus-kasus yang terjadi saat kegiatan belajar mengajar khsususnya pelajaran IPA berdasarkan kesaksian guru IPA di SMP Muhammadiyah 1 dan 2 Kalibawang diantaranya peserta didik yang bertingkah tidak sesuai peraturan sekolah dan tidak sesuai dengan etika sopan santun yang seharusnya sehingga dalam praktik kegiatan belajar mengajar guru banyak mengalami kesulitan dan tujuan pembelajaran tidak tercapai. Tak jarang peran orangtua dalam keluarga sangat dibutuhkan dalam perbaikan akhlak peserta didik. Dalam kutipan Dobbert dan Nummer (1985) dalam Djahiri (1996) menyatakan bahwa "family is the fist dominant factor and the effectively most importsant". Pernyataan ini jelas menempatkan keluarga sebagai lembaga primer dan penentu karakter diri seseorang.

Menurut Diane Tilman dalam Purwaningsih (2012) ada dua belas nilai kehidupan mendasar yang sangat perlu untuk ditanamkan kepada anak-anak guna membekali anak dalam mengarungi kehidupan di masyarakat. Nilai-nilai itu meliputi nilai kedamaian, penghargaan, cinta, toleransi, kejujuran, kerendahan hati, kerjasama, kebahagiaan, kebebasan, dan persatuan. Nilai-nilai inilah yang harus ditanamkan kepada generasi penerus agar etika, 
moral dan tanggung jawab dapat dipertahankan keagungannya ditengah masyarakat sehingga terjadi degradasi moral.

Tujuan dari penelitian ini adalah untuk menginventarisasi kasus-kasus yang terjadi saat kegiatan belajar mengajar pelajaran IPA di SMP Muhammadiyah 1 dan 2 Kalibawang. Diharapkan dapat menemukan soluso bagaimana mengkondisikan anak agar belajar dengan benar, niat, sungguh-sungguh , sesuai harapan orangtua dan guru. Juga sebagai pembelajaran untuk sekolah lain supaya tidak terjadi hal-hal yang tidak diinginkan.

\section{PEMBAHASAN}

Hasil dari penelitian ini menunjukan beberapa kasus yang terjadi pada saat pembelajaran di dalam kelas pelajaran IPA di SMP 1 dan 2 Muhammadiyah Kalibawang. Kasus-kasus ang terjadi diantaranya tidur di lantai dalam kelas. Kejadian ini terjadi di kelas 2 peserta didik tersebut duduk berjejer turun dari kursinya kemudian membawa tasnya dan tidur di lantai dengan kaki menghadap utara dan selatan, selanjutnya kasus peserta didik yang memandang gurunya seperti temannya sendiri sehingga bicaranya tidak menggunakan kata yang sopan (bahasa ngoko) terhadap guru contoh "opo bu”, "ora bu”, "wes bu”, “ngopo e bu”, curi-curi membawa HP untuk terlihat gaya dan menonton video dewasa, tugas tidak dikerjakan bahkan ada gurunya, peserta didik lebih sibuk mengganggu temannya, terkadang sibuk sendiri, bolos ke kantin, makan di kelas saat pelajaran alasan pusing diijinkan minum ternyata peserta didik tidak kembali ke kelas, merokok awalnya coba-coba merokok lantas kecanduan.Itu semua diidentifikasi dikarenakan peserta didik tidak termotivasi ikut pelajaran, tidak suka dengan pelajarannya, tidak suka dengan gurunya, peserta didik sedang dalam permasalahan internal.

Antisipasi yang dilakukan selama ini dari kasus-kasus tersebut adalah peserta didik dingatkan kembali latar belakang keluarganya semacam bimbingan langsung, bahwa orangtua sudah bekerja keras namun anaknya tidak sesuai harapan terutama orangtua. Menurut kedua guru selama ini metode yang paling ampuh adalah diingatkan tentang tujuan utama sekolah namun, dalam kenyataannya peserta didik tidak merubah perilakuknya secara berkelanjutan, suatu saat akan kambuh lagi. Karena peserta didik tidak diingatkan kembali oleh orangtua di rumahnya maka di sekolah akan kembali berulah, karena banyaknya guru yang mengajar anak tersebut dapat berubah sikap seketika itu juga tergantung kondisi siswa dan guru yang mengajar. Hal inilah yang membuat guru kesulitan dalam menyampaikan pelajaran IPA dan menghambat peserta didik lain dalam memperoleh pengetahuannya pada saat kegiatan belajar mengajar. 
Berikut ini adalah hasil inventarisasi kasus saat kegiatan belajar mengajar pelajaran IPA di SMP Muhammadiyah 1 dan SMP Muhammadiyah 2 Kalibawang.

Tabel 1.1 hasil inventarisasi kasus saat kegiatan belajar mengajar pelajaran IPA di SMP Muhammadiyah 1 dan SMP Muhammadiyah 2 Kalibawang.

\section{SMP MUHAMMADIYAH 1 KALIBAWANG}

1. Malas-masalan mengikuti pelajaran,

2. Ngobrol sewaktu pelajaran,

3. Tidur di kelas sampai di lantai kelas,

4. Tidak menggunakan bahasa yang sopan "bahasa ngoko",

5. Membolos saat masih KBM (ada tapi hanya dua anak yang benar-benar bandel)

6. Guru muda yang dianggap sebagai temannya sendiri

7. Banyak tugas tidak dikerjakan bahkan ada gurunya

\section{SMP MUHAMMADIYAH 2 KALIBAWANG}

1. Bolos ke kantin Makan di kelas saat pelajaran,

2. Ngobrol sewaktu pelajaran,

3. Tidur di kelas karena kecenderungan malas-masalan mengikuti pelajaran

4. Tidak menggunakan bahasa yang sopan "bahasa ngoko" karena guru muda sehingga dianggap sebagai temannya sendiri

5. Curi-curi membawa HP dan merokok

6. Banyak tugas tidak dikerjakan bahkan ada gurunya

\section{SIMPULAN}

Hasil dari penelitian ini Pada SMP Muhammadiyah 1 Kalibawang terdapat 7 kasus dan SMP Muhammadiyah 2 Kalibawang terdapat 6 kasus. Di ke 13 kasus terebut 4 kasus yang sama. Yaitu membolos ke kantin sewaktu pelajaran, ngobrol pada saat pembelajaran, tidur di kelas, tidak mengguanakan bahasa yang sopan kepada gurunya, dan tugas-tugas yang tidak dikerjakan saat pembelajaran.

\section{REFERENSI}

Bencsik, A., Csikos, G., \& Juhaz, T. (2016). Y and Z Generations at Workplaces. Journal of Competitiveness, 8(3), 90-106. https://doi.org/10.7441/joc.2016.03.06

Djahiri, A. K. (1996). Menelusuri Dunia Afektif. Bandung: Lan Pengajaran PMP IKIP.

Purwaningsih, E. (2012). Keluarga Dalam Mewujudkan Pendidikan Nilai Sebagai Upaya Mengatasi Degradasi Nilai Moral. Jurnal Pendidikan Sosiologi dan Humaniora, 1(1).

Putra, Y. S. (2017). Theoritical review: Teori perbedaan generasi. Jurnal Ilmiah Among Makarti, 9(18).

Widianto, E. (2015). Peran Orangtua Dalam Meningkatkan Pendidikan Karakter Anak Usia Dini Dalam Keluarga. Jurnal PG-PAUD Trunojoyo: Jurnal Pendidikan dan Pembelajaran Anak Usia Dini, 2(1), 31-39. 